\title{
A cross-sectional national survey assessing self-reported drug intake behavior, contact with the primary sector and drug treatment among service users of Danish drug consumption rooms
}

Eva Charlotte Toth ${ }^{*}$, Jette Tegner ${ }^{1}$, Sigurd Lauridsen ${ }^{2}$ and Nanna Kappel ${ }^{1}$

\begin{abstract}
Background: Drug consumption rooms (DCRs) have been implemented worldwide as a harm-reducing strategy. In 2012, Denmark passed legislation allowing establishment of DCRs. The aim of this study was to identify characteristics and gain knowledge of the way service users use the DCRs including bridge building to specialized health care. Associations between nationality, opioid substitution treatment (OST), drug intake method, and response to staff advice on harm-reducing education was investigated, as well as service user's reasons for using the DCRs, and their perceptions of safety and trust in the DCRs.

Methods: A survey questionnaire sampled 154 participants of DCRs. Convenience sampling was used. Key variables covered demographics, drug intake mode, educational advice received in the DCR, and opinions about and role of the DCRs for the service users.

Results: Only $10 \%$ of the participants were under the age of 30, $30 \%$ between 30 and 39 years, $36 \%$ between 40 and 49 years, and $24 \%$ age 50 or more. A total of $60 \%$ of the participants had encountered drugs before they were 19 years old. Female participants were $25 \%$, and $73 \%$ were Danish citizens, $8 \%$ were non-Danish EU citizens, and $18 \%$ were non-EU citizens. As drug intake method, $63 \%$ injected drugs in a vein, $7 \%$ sniffed, and $37 \%$ smoked. Of drugs used in the DCR, $49 \%$ used cocaine, $41 \%$ heroin, $16 \%$ a mix of heroin and cocaine, and $16 \%$ used methadone. Participants who smoked drugs made significantly less use of drug rehabilitation than participants who sniffed or injected drugs. There was a similar rate of advice on OST across nationality. Participants accepted staff education on hygienic measures and safe injection practices and found it useful. Participants felt safe and trusted staff and bridge building to specialized health care took place in the DCR.

Conclusions: Staff of Danish DCRs educate service users on health related issues and harm-reducing interventions. A subgroup who smoke and a subgroup of nationality other than Danish are underserved and have less likely been in OST. More research on these groups is needed.
\end{abstract}

Keywords: Drug consumption room, Harm reduction, Smoking facility

\footnotetext{
* Correspondence: ecto@phmetropol.dk

'Department of Nursing, Metropolitan University College, Copenhagen, Denmark

Full list of author information is available at the end of the article
} 


\section{Background}

Illicit drug use is associated with a range of social and environmental harms. The lack of safe environments in which to consume drugs poses a high risk to people who use drugs (PWUD) and drug intake often takes place in public spaces [1-3]. Public drug use contributes to unhygienic injection techniques, causing tissue damages and infections $[4,5]$, and has negative consequences on the health of PWUD. In major Danish cities, drugs are frequently consumed under stressful and unsafe conditions in public spaces that serve as open drug scenes. PWUD feel ashamed of using drugs in public areas and the exposure of public injecting damages the reputations of individual PWUD [6, 7]. Around open drug scenes, public opinion calls for urban renewal, tidy surroundings, and clean playgrounds. Citizens around open drug scenes, including families with children, have expressed concern over public injecting in the local surroundings [8]. Over the previous 20 years, the number of people in Denmark who die due to drug overdose fluctuates somewhat but averages about 250 people per year $[9,10]$.

To reduce harm and prevent overdose caused by unsafe drug consumption, various harm reduction policies have been implemented by the Danish Ministry of Health, such as needle exchange programs, free drug treatment and opioid substitution treatment (OST) [10]. By establishing low threshold facilities to reach the vulnerable and socially marginalized PWUD, it is possible to offer health care and build bridges that lead to more specialized health care, OST, and drug-free treatment [6].

One such harm reduction policy is the establishment of supervised drug consumption rooms (DCRs), which have been established worldwide to reducing the harm to which PWUD are exposed [11-13]. A DCR is defined as a "professionally supervised health care facility where drug users can use drugs in safer and more hygienic conditions" [10] than street-based drug using. Over the past 25 years, DCRs have been implemented in several European countries [12] as well as in Australia and Canada [10]. Internationally, the effectiveness of DCRs in harm reduction has been supported by several studies. DCRs attract people with chronic use of drugs, who have increased health risk [14], contribute toward reducing the transmission of infectious diseases such as HIV and hepatitis $\mathrm{C}$, and offer the treatment of infectious wounds [13-20].

In 2012, Denmark passed legislation allowing municipalities to establish DCRs. The bill amending the law presumes that "... within the vicinity of the DCRs, police will not prosecute people who are over the age of 18 years, who possess drugs for their own use, and who have a prolonged use of and addiction to illicit drugs" [7]. The motivation behind this political decision was threefold: to reduce the number of deaths by overdose; to improve life options for PWUD by building bridges to the health care system, drug treatment facilities, and social services; and to reduce drug use related nuisance to surrounding neighborhoods [7]. In the 3 years following this landmark decision, the three largest cities in Denmark have established DCRs. DCRs are organized as integrated, specialized, or mobile models $[10,12]$. Currently, more than 3600 service users are registered in Danish drug consumption rooms. Danish DCRs mainly provide service to highly marginalized PWUD, in many cases including OST clients with patterns of stimulant use.

Few studies to date have examined the Danish DCRs. One study of one of the Copenhagen DCRs shows that service users adopt safer behaviors that reduce harm and benefit health [21] and a recent evaluation of the DCRs finds a positive effect on overdose prevention. Other than these, no national study has been performed identifying characteristics of this population and the mode of drug use in the DCRs, nor in assessing the service users' utilization of the harm reductive interventions delivered in the DCR.

For this reason, this national research study that covers all of the existing DCRs in Denmark was initiated in December 2013. The aim of this article is to identify characteristics of the service user population and gain knowledge of the way service users use the DCRs, including bridge building to specialized health care. Further, we investigate associations between nationality, OST, drug intake method, and response to staff advice on harm-reducing education. Finally, we investigate service users' reasons for using the DCRs, their perceptions of safety and trust in the DCRs.

\section{Methods}

This paper reports a subset of results from a larger mixed method study of Danish DCRs [22]. Based on reports and files from the five DCRs in Denmark that assess the number of service users, types of drugs, and routes of administration [23, 24], a mixed method study was designed using an explanatory sequential design $[22,25]$.

The first part of the mixed method study comprised of $250 \mathrm{~h}$ of participant observation performed in the DCRs in Denmark. The second part comprised of semistructured interviews with 25 staff and 40 service users of the DCRs [22]. The third part of the study was a structured face-to-face interview survey questionnaire designed to gather information on areas of interest such as health, drug intake habits, and contact with drug treatment centers, identified in the qualitative part of the study. This article is based on results of the survey questionnaire. 


\section{Study population}

The investigation covers all five DCRs in Denmark. The five DCRs vary in setup and service. In the city of Odense, the DCR is part of a shelter and has a free needle exchange program. It is staffed by social workers, social educators, and nursing aides who provide health assistance. The service users have access to showers, laundry facilities, and free meals. The DCR in the city of Aarhus is also part of a shelter. It has an injection facility and a smoking facility reserved for smoking drugs such as heroin and cocaine, and a health clinic. Two DCRs in Copenhagen are part of a shelter, one of which operates $23 \mathrm{~h}$ a day and is integrated within a network of services such a health clinic and access to counselling. The facility has booths for injecting and a separate room for smoking. The other DCR is associated with a health clinic, but lacks a smoking facility. There is approximately a 30-min time limit to the length of stay in these two facilities. The third DCR in Copenhagen is a mobile DCR, which is staffed only by nurses, and has room for four service users at a time. There is unlimited and free access to drug paraphernalia in the Aarhus and Copenhagen DCRs. Paraphernalia is equipment such as syringes, needles, alcohol wipes, sterilized water, sets for cooking heroin, smoking foil, bicarbonate, smoking sets, and other tools used for drug intake. There is no limit to the length of stay in the mobile facility or the facilities in Odense and Aarhus. In 2014, there were 3564 unique service users registered at the five DCRs [8]. Our sample consisted of 154 service users of DCRs in Denmark. However, not all registered service users from 2014 were active service users at the time the survey was conducted in January 2015. Active service users are here defined as persons who are currently registered visitors of the DCR. This number varies as clients are sometimes absent for a period; some go to drug rehabilitation, some to jail, travel, or do not use the DCRs for a while and then they may appear again. For example, at one DCR (Aarhus), there were 205 registered service users since opening of the DCR, but only 35 were visiting the DCR at the time the survey was conducted. Because of this, it has not been possible to determine the precise size of the client pool nor was it possible to determine the degree to which our sample represents the population of service users of the DCRs.

\section{Survey instrument and administration}

A survey was developed to be administered in the form of face-to-face interviews. As no Danish validated survey assessing health impact of DCRs on service users exists, this survey has been developed to fit the local Danish context. Expert panel validation was used and parties involved were the head physician of an addiction treatment center, the chiefs of staff and staff members from the DCRs, professional researchers experienced in survey design, a statistician, a researcher in the field of drug use, and associate professors involved in the study who have experience in approaching PWUD and engaging them in the study. Two pilot tests were conducted prior to the final survey. Each pilot test was followed by review in expert panel group sessions. The survey had 42 questions and took about 10-15 min to complete. It was administered on tablet computers using the Enalyzer Survey Solution System online [26].

All interviews were conducted between 5th January 2015 and 2nd February 2015. DCR staff was helpful in informing service users about the study and encouraging participation. Informational posters about the project were visible in the DCRs during the survey process. To gain heterogeneity, time of day and week varied to cover all possible opening hours. Some DCRs have extended opening hours following the so-called pay days, where people receive money (social benefits, retirement pension, etc.) due to extraordinarily high activity. Thus, interviews were conducted on weekdays and weekends, in the daytime and nighttime as well as on pay days and in between pay days. To avoid bias in regard to answering sensitive questions, no staff from the DCRs administered the questionnaires. The researchers undertook the study, in collaboration with nursing students who were carefully recruited and trained. The nursing students collectively interviewed 10 service users; the rest of the 154 interviews were conducted by the researchers. Convenience sampling was used. Eligible participants were current service users of the DCRs, age over 18 years, who smoke, sniff or inject drugs. Participants were required to have an adequate understanding of Danish in order to complete the interview survey without translation. Participants were recruited in the vicinity of the DCRs or inside the waiting areas and sampled consecutively. Total hours of data collection and total number of participants at each site were stratified and weighted according to the number of registered service users in the DCRs [27-29], to ensure adequate representation of possible subgroups. However, we had to spend additional time in the DCR with the fewest service users to recruit participants (Table 1).

An interviewer approached the interviewee to describe the purpose of the survey and inform of the anonymity. Face-to-face interviews were conducted and answers were entered on computer tablets. Data was exported from Enalyzer to the statistical programs SPSS and R system for statistical analysis [30, 31]. Bivariate analysis was done for groups and subgroups of variables. Descriptive statistics were performed to summarize data. Categorical table analysis was performed to examine the associations between categorical exposures and outcome variables using Fisher's exact test and chi-squared test. 
Table 1 Data collection

\begin{tabular}{llll}
\hline & $\begin{array}{l}\text { Registered service } \\
\text { users at time of survey }\end{array}$ & $\begin{array}{l}\text { Hours of survey } \\
\text { data collection }\end{array}$ & $\begin{array}{l}\text { Number of } \\
\text { participants } \\
n\end{array}$ \\
\hline Aarhus & 205 & 11 & 5 \\
Odense & 375 & 28 & 38 \\
The mobile unit & 270 & 8 & 8 \\
Halmtorvet & 1174 & 30 & 22 \\
Skyen & 2348 & 97 & 81 \\
\hline
\end{tabular}

Numbers of refusals to participate were 40 . Out of respect for refusal to participate, no information on service users who refused were collected. In order to avoid double participation, service users were asked whether they had already been interviewed. A total of 146 of the 154 questionnaires were fully completed. Because some of the service users were recruited in the waiting area of the DCRs while they were in line to enter, eight of the questionnaires were not completed in full, as the service users were called in to the DCR before the survey interview was completed. Missing data were deleted in order to make a complete case analysis. Questionnaire domains were demographics, pattern of using DCRs, drug intake method, drugs used, drug rehabilitation, advice received at DCRs, overdose experience, contacts to health care, service users' opinion about DCRs, and role of DCRs in rehabilitation. The STROBE Statement, whose aim is to strengthen the reporting of observational studies in epidemiology, was used to prepare this manuscript [32].

\section{Results}

\section{Demographics of Danish DCR service users}

To identify characteristics of this population, service users were asked about demographics, drug intake mode, disease status, and incarceration. As shown in Table 2, most participants of the survey were above 30 years of age-only $10 \%$ were under the age of 30 . Only $25 \%$ of the participants were female, which is equivalent to the normal distribution ratio seen for gender in this population in Denmark [10]. Most participants had encountered drugs at a young age, and $60 \%$ reported starting to use illicit drugs (like heroin and cocaine but not cannabis) before they were 19 years old. Danish citizens comprised $73 \%$ of the participants, nonDanish EU citizens made up $8 \%$, and $18 \%$ had non-EU citizenship. In the two smaller cities, Aarhus and Odense, all participants in the sample were Danish. A total of $70 \%$ were single and $30 \%$ cohabiting, and $45 \%$ had no children. In response to the labor market attachment, participants were asked whether they were employed full-time or part-time, in job training, or students. These categories were grouped as working full or part time. Only $11 \%$ of participants had full- or parttime work, $44 \%$ were receiving social welfare payments, and $38 \%$ were on early retirement. The group "other" covered no source of income or income by selling magazines specially provided for unemployed PWUD to sell. In regard to housing, the participants were asked whether they had stable or unstable housing, unstable housing being defined as being homeless, living in a shelter, on the street, or irregular sleeping accommodations with friends. In this sample, $60 \%$ had stable housing.

Only $1 \%$ inject subcutaneously, $63 \%$ inject intravenously, $7 \%$ sniff, and $37 \%$ smoke. Of all participants who injected drugs, $87 \%$ are Danish. Some participants reported more than one method of intake. A total of $80 \%$ used the DCRs more than once a week and $42 \%$ used DCRs more than five times a week. Furthermore, $71 \%$ used the DCRs more than twice a day, and $22 \%$ used it more than five times a day. Clearly, some participants were very frequent service users of the DCRs.

A total of $39 \%$ report being infected with hepatitis $\mathrm{C}$ virus (HCV), $9 \%$ with hepatitis B (HBV), $3 \%$ with $\mathrm{HIV}$, and $3 \%$ with tuberculosis. There is a significantly higher prevalence of $\mathrm{HCV}$ among participants who injected drugs compared to those who smoke drugs $(p=0.000)$. Of the 96 persons who inject drugs, 48 persons $(53 \%)$ had $\mathrm{HCV}$. Of the 55 persons who smoked, and answered questions on disease, only 9 persons or $17 \%$ of the smoking group had HCV (Table 3). Of the 146 participants who completed the questionnaire in full, $81 \%$ had been in prison, only $14 \%$ answered that they had never been in prison and $5 \%$ declined to respond (Table 2). Further cross analysis shows that $47 \%$ had been in prison more than five times and $60 \%$ of those who had been incarcerated were between the ages of 9-19 when they started using illicit drugs (Table 2). When examining the relationship between disease status and incarceration, only $5 \%$ of those who have $\mathrm{HCV}$ had never been in prison $(p=0.034)$ and all persons who reported having HIV had spent time in prison (Table 2).

\section{Associations between nationality, OST, drug intake method, and response to staff advice on harm-reducing education}

This study also examined the associations between nationality, type of drug used, and OST; in this Danish context, OST is defined as methadone, buprenorphine, or heroin-assisted treatment. Participants were asked whether they were currently in drug rehabilitation treatment like OST, had been in treatment or had never been 
Table 2 Demographic characteristics and drug intake mode of participants of DCRs $(n=154)$

\begin{tabular}{ll}
\hline & Total \\
$n(\%)$ \\
$154(100)$
\end{tabular}

Age, years

20-29
30-39
40-49
$\geq 50$
Gender
Male

Female

Age at first time of hard drug use, years ${ }^{a}$

$$
\begin{aligned}
& 9-19 \\
& 20-29 \\
& 30-39 \\
& \geq 40
\end{aligned}
$$

Nationality ${ }^{a}$

Danish citizenship

EU citizenship other than Danish

Non-EU citizen

Residence status

Single

Cohabiting

Parental status

No children

Children

Work status

Full time/part time work
Social welfare
Early retirement
Other
Housing status
Stable
Unstable
Drug intake method
Inject in a muscle or subcutaneous
Inject in a vein
Sniff
Smoke

Drugs used

Cocaine

Heroin

Mix of heroin and cocaine

Methadone

Benzodiazepines
Table 2 Demographic characteristics and drug intake mode of participants of DCRs $(n=154)$ (Continued)

$\begin{array}{ll}\text { Ritaline } & 5(3) \\ \text { Amphetamines } & 3(2)\end{array}$

Frequency of DCR use per week

$15(10)$

Less than 1 day a week

$30(20)$

1 day a week

$17(11)$

2-4 days a week

$42(27)$

5-7 days a week

$65(42)$

Frequency of use of DCR per day

$116(75)$

1 time per day

45 (29)

$38(25)$

2-5 times per day

75 (49)

More than 5 times per day

$33(22)$

$93(60)$

Disease status

42 (27)

Hepatitis C virus (HCV)

56 (39)

$14(9)$

5 (3)

Hepatitis B virus (HBV)

$13(9)$

HIV

5 (3)

Tuberculosis

$5(3)$

None of these

$80(55)$

13 (8)

Incarceration $^{\text {b }}$

28 (18)

Spent time in prison

$118(81)$

Never been to prison

$21(14)$

$108(70)$

46 (30)

Prefer not to answer

$7(5)$

Incarcerated 1-5 times

$62(53)$

6-10 times

32 (28)

11-50 times

$22(19)$

$66(45)$

Use of health care system the past 3 months

Health care clinic in or close to DCRs

$44(30)$

Street nurse

9 (6)

16 (11)

General practitioner

$44(30)$

65 (44)

Emergency room

24 (16)

$11(7)$

Hospitalization

$22(14)$

Outpatient contact

24 (16)

None of the above

$55(37)$

$92(60)$

$62(40)$

$1(1)$

96 (63)

$10(7)$

$56(37)$

${ }^{a}$ Total is 99 due to rounding error

b Only three (5\%) with HCV have never been in prison, Pearson chi-square $p=0.034$. All participants with HIV have spent time in prison. $N 71$ (60\%) of those who spent time in prison, were age 9-19 when they started using illicit drugs

in treatment. As shown in Table 3, a total of $91 \%$ of participants with Danish nationality were or had been in OST treatment. Of non-EU participants, only $70 \%$ were or had been in OST and $83 \%$ of those with other EUcitizenship than Danish had been or were in OST. Hence, significantly more Danish citizens than both other EU and non-EU citizens were or had been participating in OST $(p=0.016)$. An analysis of participants who smoke drugs revealed that they make significantly 
Table 3 Opioid substitution treatment (OST)

$n(\%)^{a} \quad p$

Is or have been in OST

Nationality ${ }^{b}$

Danish

EU other than Danish

Non-EU citizen

Yes

No

Drug intake method

Smoke
Inject or sniff

Drug intake method

Nationality ${ }^{d}$

Danish

EU other than Danish

Non-EU citizen

Total

Disease status $^{\mathrm{e}}$

$\mathrm{HCV}$

HBV

HIV

Tuberculosis

None of these

Total

Advised on OST

$\begin{array}{lll} & \text { Yes } & \text { No } \\ \text { Nationality (total) }^{f} & & \\ \text { Danish } & 30(67) & 82(77) \\ \text { EU other than Danish } & 11(24) & 16(15) \\ \text { Non-EU citizen } & 4(9) & 8(8) \\ \text { Total } & 45(100) & 106(100) \\ \text { Nationality (advised OST) } & \\ \text { Danish } & 45(30) & 106(70) \\ \text { EU other than Danish } & 30(27) & 82(73) \\ \text { Non-EU citizen } & 11(41) & 16(59) \\ \text { Nationality (smokers) } & 4(33) & 8(67) \\ \text { Danish } & 11(38) & 18(62) \\ \text { EU other than Danish } & 1(33) & 2(67) \\ \text { Non-EU citizen } & 9(39) & 14(61) \\ \text { Drug intake method' } & & \\ \text { Smoke } & 21(38) & 34(62) \\ \text { Inject or sniff } & 24(25) & 72(75)\end{array}$

0.016

Table 3 Opioid substitution treatment (OST) (Continued)

\begin{tabular}{lll}
\hline Is or have been in OST & & \\
Yes & $37(28)$ & $94(72)$ \\
No & $8(40)$ & $12(60)$ \\
\hline
\end{tabular}

${ }^{a}$ The number in parentheses is the percentage of the noted subgroup

${ }^{\mathrm{b}}$ Fisher's exact test comparing nationality against have been in OST.

Significantly more Danish have been in OST. Of the entire sample, only $30 \%$ $(n=45)$ have been advised on OST

'Chi-squared test comparing drug intake method against have been in OST. Significantly more inject/sniff have been in OST

${ }^{\mathrm{d} C h i-s q u a r e d ~ t e s t ~ c o m p a r i n g ~ n a t i o n a l i t y ~ a g a i n s t ~ d r u g ~ i n t a k e ~ m e t h o d . ~}$

Significantly more who inject/sniff are Danish, and significantly more who smoke are of other nationality than Danish

${ }^{e}$ Chi-squared test comparing disease status against drug intake method.

Significantly more with HCV inject

${ }^{\mathrm{f}}$ Chi-squared test comparing nationality within against advised on OST. Within the group who have been advised, a total of $67 \%(n=30)$ are Danish and a total of $33 \%(n=15)$ are of other nationality than Danish

${ }^{9}$ Fisher's exact test comparing nationality against advised on OST. Within the advised Danish group $27 \%(n=30)$ of the Danes had been advised and $73 \%$ $(n=82)$ of the Danes had not

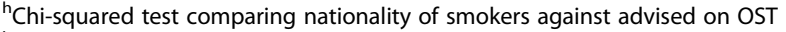

'Chi-squared test comparing drug intake method against advised on OST

${ }^{\mathrm{j}} \mathrm{Chi}$-squared test comparing have been in OST against advised on OST

0.000

less use of drug rehabilitation programs than participants who sniff or inject drugs $(p=0.002)$. While $25 \%$ of the smoking group had never been in OST, only $6 \%$ $(n=6)$ of those who injected had never been in OST (Table 3).

All participants were asked whether they had been advised by staff of the DCRs about how to enter drug rehabilitation like OST. Only 45 persons, which were $30 \%$ of the total sample, reported having been advised of the opportunity to enter drug treatment program. Of participants who reported to having been advised on OST, $67 \%(n=30)$ were Danish citizens and $33 \%(n=15)$ were of other nationality than Danish (Table 3). Of the total Danish group (Table 3), $27 \%(n=30)$ had been advised on OST and $73 \%(n=82)$ had not. Of the total group whose nationality was EU other than Danish, $41 \%(n=11)$ had been advised on OST, and $59 \%(n=$ 16) had not; of the non-EU citizens, $33 \%(n=4)$ had been advised on OST and $67 \%(n=8)$ had not. Among all people advised on OST, there is no nationality difference. Within drug intake method, only $38 \%(n=21)$ of those who smoked and $24 \%(n=25)$ of those who sniffed or injected reported having been advised on OST (Table 3). A further analysis of participants who smoke drugs showed significantly more $(p=0.000)$; in fact, $48 \%$ $(n=25)$ of participants who smoke drugs were of other nationalities other than Danish, whereas only $13 \%(n=$ 13) of those who injected drugs were of other nationalities other than Danish (Table 3). Further analysis on the group who smoke shows that when comparing against nationality, they are advised at an almost similar rate, Danish 38 \%, EU other than Danish 33 \%, and non-EU $39 \%$ respectively (Table 3 ). 


\section{Contacts to specialized health care and harm-reducing education}

The study also examined contacts to specialized health care and how service users respond to staff advice on health-related issues and harm-reducing education in relation to safer drug use practices. Therefore, participants were asked which types of contact with health care providers the service user had had within the previous 3 months (Table 2) as well as if they have received treatment for disease within the past 2 years, which is the time the DCRs have existed at the time of the survey. Some of the participants had several contacts, and $37 \%$ had no contact with these most common health care system facilities (Table 2). When asked whether participants had been advised to seek medical attention for signs of disease observed by staff, $39 \%(n=57)$ of participants responded positively. Of those advised to seek medical attention, $68 \%$ had also been in treatment for disease within the past 2 years, which could indicate that participants who are advised to seek medical attention follow given advice as there was a significant relationship between being advised to seek medical attention and having been in treatment for disease $(p=0.003)$ (Table 4).

As seen in Table 4, $57 \%(n=55)$ of the total number of participants who inject $(n=97)$ had previously been educated by staff at the DCR in safe injection practices, which are defined as follows: use of tourniquet, injecting in the right direction in relation to the heart, change of injection site, change of needle at each perforation of the skin, and use of vein scanning device. Among those who received education, a total of $95 \%$ found it to be useful. Furthermore, $61 \%(n=62)$ of the participants who injected had been educated in hygienic measures, such as hand washing before injecting, the cleansing of injection site with an alcohol swab before injecting, and the use of sterile water for dissolving the drug. Out of those, $98 \%$ found the education to be useful. Also, the service users who have been educated in hygiene reported that they use the DCRs because of access to clean tools to a higher degree than those that had not been educated (Table 5).

A total of $13 \%(n=20)$ of the sample had experienced an OD inside the DCR and $50 \%(n=76)$ had experienced an OD inside the DCR. Analysis shows there is a correlation between having experienced an OD either inside (Table $4, p=0.0042$ ) or outside (Table $4, p=0.018$ ) of a DCR and perceived ability to prevent an OD since starting to use the DCR (Table 4). Analysis on service users who inject showed that $54 \%$ of service users reported becoming better at preventing OD since starting to use the DCR and that $55 \%$ used the DCR to avoid dying from OD (Table 6).

This study also examined how important participants find the DCRs in terms of becoming drug free and the
Table 4 Advice, education, and overdose

\begin{tabular}{|c|c|c|c|}
\hline & \multicolumn{2}{|l|}{$n(\%)$} & \multirow[t]{2}{*}{$p$} \\
\hline & Yes & No & \\
\hline \multicolumn{4}{|l|}{ Treatment for disease } \\
\hline \multicolumn{4}{|l|}{ Advised to seek medical help ${ }^{a, b}$} \\
\hline Yes & $39(68)$ & $18(32)$ & 0.003 \\
\hline No & $37(42)$ & $52(38)$ & \\
\hline \multicolumn{4}{|l|}{ Was the education useful? } \\
\hline \multicolumn{4}{|l|}{ Have been educated by staff in: } \\
\hline Safe injection n 55 (100) & $52(95)$ & $3(5)$ & \\
\hline Hygienic measures n 62 (100) & $61(98)$ & $1(2)$ & \\
\hline \multicolumn{4}{|c|}{ Use DCR because of access to clean tools } \\
\hline \multicolumn{4}{|l|}{ Educated in hygienic measures ${ }^{c}$} \\
\hline Yes & $55(93)$ & $4(7)$ & 0.024 \\
\hline No & $25(76)$ & $8(24)$ & \\
\hline \multicolumn{4}{|c|}{ Become better at preventing overdose since using DCR } \\
\hline \multicolumn{4}{|c|}{ Experienced overdose inside DCR ${ }^{d}$} \\
\hline Yes & $16(80)$ & $4(20)$ & 0.0042 \\
\hline No & $54(43)$ & $75(57)$ & \\
\hline \multicolumn{4}{|l|}{ Experienced overdose outside DCR } \\
\hline Yes & $44(58)$ & $32(42)$ & 0.018 \\
\hline No & $28(37)$ & $47(63)$ & \\
\hline
\end{tabular}

${ }^{a} N 57$ (which is $39 \%$ of the total sample) had been advised on seeking medical help

${ }^{\mathrm{b} C h i-s q u a r e d ~ t e s t ~ c o m p a r i n g ~ a d v i s e d ~ t o ~ s e e k ~ m e d i c a l ~ h e l p ~ a g a i n s t ~ h a v e ~ b e e n ~}$ in treatment. Significantly more who have been advised have also been in treatment

'Fisher's exact test shows significantly more who have been educated in hygienic measures use DCR because of access to clean tools

${ }^{d}$ Chi-squared test shoving significant correlation between having experience of $O D$ inside $D C R$ to perceived ability to prevent an $O D$ since starting to use the DCR

${ }^{\text {e}}$ Chi-squared test shoving significant correlation between having experience of OD inside DCR to perceived ability to prevent an OD since starting to use the DCR

extent to which they believed in a drug-free future for themselves. Many service users reported a belief in a drug-free future and $90 \%$ of those indicated that the DCRs was of great importance for becoming drug free. However, note that analysis indicated no significance in this outcome, although the $p$ value was nearly significant $(p=0.052$, Table 5), suggesting the value of further inquiry.

\section{Reasons for using the DCRs and perceptions of security} We next examined possible reasons among the service users for using the DCRs and service users' perceptions of security in the DCRs. Therefore, participants of the survey were presented with questions regarding why they use the DCRs and how they feel about the DCRs. They were asked whether they use DCRs because of access to clean tools, avoiding public drug intake, whether they use DCRs to assist in preventing overdose, how 
Table 5 Belief in becoming drug free and education on hygienic measures

\begin{tabular}{|c|c|c|c|c|c|c|}
\hline Importance of DCR for becoming drug-free & Great importance & Some importance & Less importance & No importance & Total $n(\%)$ & $p$ \\
\hline Own belief in becoming drug free in the future ${ }^{a}$ & & & & & & 0.052 \\
\hline Believe to great extent & $27(66)$ & $10(40)$ & $7(50)$ & $25(38)$ & $69(47)$ & \\
\hline Believe to some extent & $10(24)$ & $10(40)$ & $4(29)$ & $22(33)$ & $46(31)$ & \\
\hline Believe to lesser extent & $3(7)$ & $5(20)$ & $3(21)$ & $10(15)$ & $21(14)$ & \\
\hline Believe to no extent & $1(2)$ & $0(0)$ & $0(0)$ & $9(14)$ & $10(8)$ & \\
\hline Total n (\%) & $41(100)$ & $25(100)$ & $14(100)$ & $66(100)$ & $146(100)$ & \\
\hline \multicolumn{7}{|l|}{ Use the DCR because of access to clean tool $n(\%)$} \\
\hline & Yes & No & Don't know & & & \\
\hline Have been educated in hygiene ${ }^{b}$ & & & & & & 0.01 \\
\hline Yes & $55(93)$ & $4(7)$ & $0(0)$ & & $59(100)$ & \\
\hline No & $25(71)$ & $8(23)$ & $2(6)$ & & 35 (100) & \\
\hline
\end{tabular}

${ }^{a}$ Monte Carlo chi-squared test comparing own belief in drug free future against importance of DCR for a drug-free future

${ }^{b}$ Fisher's exact test showing significantly more who have been educated in hygiene use DCR because of access to clean tools

important they found the DCRs in relation to becoming drug free in the future, and whether they trust staff and feel safe in the DCRs. There was a significant effect of having been educated in good hygiene on reporting use of DCRs because of access to clean equipment $(p=0.01$, Table 5). Seventy-four percent of all the participants reported using the DCR because of access to clean tools. The participants were conscious that their public drug use bothers the people in the area and $71 \%$ reported that one reason for using the DCR was to avoid bothering people in the neighborhood. In regard to the participants' trust in staff and feeling safe, $88 \%$ reported trusting staff and $89 \%$ reported feeling safe in the DCRs (Table 6).

\section{Analyses by site}

Finally, we compared the different DCRs to determine if there were differences in the population and services received (Table 7). In the DCRs in the two smaller cities of Odense and Aarhus, participants were exclusively Danish. In the Skyen facility in Copenhagen, where there is a busy smoking facility, there were the highest number of non-EU citizens and also the lowest number of female participants. However, only five participants were recruited in Aarhus, none of whom were female, which

Table 6 Perceptions and reasons for using DCR

\begin{tabular}{|c|c|c|c|}
\hline$n 147(100)$ & Yes $n(\%)$ & No $n(\%)$ & Don't know \\
\hline Coming not to bother surroundings & $105(71)$ & $36(25)$ & $6(4)$ \\
\hline Trust staff & $129(88)$ & $11(8)$ & $7(4)$ \\
\hline Feel safe & $131(89)$ & $15(10)$ & $1(1)$ \\
\hline Coming for access to clean tools & $108(74)$ & $34(23)$ & $5(3)$ \\
\hline Come here to avoid OD ${ }^{\mathrm{a}}$ & $55(55)$ & $41(44)$ & $1(1)$ \\
\hline Become better at preventing OD & $52(54)$ & $45(46)$ & \\
\hline
\end{tabular}

${ }^{\mathrm{a}}$ Only injecting service users may not sufficiently represent the true gender ratio. The participants in Skyen also had a high frequency of DCR use per week as $53 \%$ of participants use the DCR 57 days a week and $31 \%$ of those use the DCR more than five times per day. In all the DCRs, there is a focus on medical advice; however, Skyen and Aarhus have the most PWUD who do not receive advice. Skyen is the place where the fewest ( $52 \%$ ) had been educated in safe injection and the only place where not all who had received this education found it useful. In all the other facilities, all the participants found education in safer injection practice and hygienic useful.

\section{Discussion}

The Danish DCRs appear to be working well in several respects; however, a subgroup of service users of nationalities other than Danish deserves more attention. Across sites, the non-Danish group had participated less in OST. While we thought it would be more difficult to make contact with the service users of non-Danish nationality, they were advised on OST at an almost similar rate. However, still $61 \%$ of the non-EU citizens who smoke were not advised and significantly fewer who smoked had been in OST. Since the non-EU citizens may also be underrepresented in our study, this subgroup could be larger than the study shows. In the qualitative part of this national study, the DCR with a smoking section in Copenhagen is seen as the largest and busiest, with service users of many nationalities [22]. This study confirms the busy scene as Skyen has the highest percentage of PWUD who use the facility 57 days a week and up to $31 \%$ who use the facility more than five times per day. Here, there were also the lowest percentage who received educational advice and the lowest percentage of participants who found the education useful (Table 7). The language barrier makes it difficult 
Table 7 Analysis by site

\begin{tabular}{|c|c|c|c|c|c|}
\hline$n(\%)$ & Mobile, Copenhagen & Halmtorvet, Copenhagen & Skyen, Copenhagen & Odense & Aarhus \\
\hline \multicolumn{6}{|l|}{ Nationality } \\
\hline Danish & $6(75)$ & $13(59)$ & $51(63)$ & $38(100)$ & $5(100)$ \\
\hline EU other than Danish & $2(25)$ & $7(32)$ & $4(5)$ & $0(0)$ & $0(0)$ \\
\hline Non-EU citizen & $0(0)$ & $2(9)$ & $26(32)$ & $0(0)$ & $0(0)$ \\
\hline \multicolumn{6}{|l|}{ Gender } \\
\hline Male & $4(50)$ & $16(73)$ & $66(82)$ & $25(66)$ & $5(100)$ \\
\hline Female & $4(50)$ & $6(27)$ & $15(18)$ & $13(34)$ & $0(0)$ \\
\hline \multicolumn{6}{|l|}{ Frequency of DCR use per week } \\
\hline Less than 1 day a week & $3(38)$ & $5(23)$ & $8(10)$ & $14(37)$ & $0(0)$ \\
\hline 1 day a week & $3(38)$ & $2(9)$ & $7(9)$ & $4(11)$ & $1(20)$ \\
\hline 2-4 days a week & $0(0)$ & $7(32)$ & $23(28)$ & $9(24)$ & $3(60)$ \\
\hline 5-7 days a week & $2(25)$ & $8(36)$ & $43(53)$ & $11(29)$ & $1(20)$ \\
\hline \multicolumn{6}{|c|}{ Frequency of use of DCR per day } \\
\hline 1 time per day & $4(50)$ & $5(24)$ & $20(25)$ & $15(40)$ & $1(20)$ \\
\hline 2-5 times per day & $4(50)$ & $10(48)$ & $36(44)$ & $21(55)$ & $4(80)$ \\
\hline More than 5 times per day & $0(0)$ & $6(28)$ & $25(31)$ & $2(5)$ & $0(0)$ \\
\hline \multicolumn{6}{|l|}{ Advised to seek medical help } \\
\hline Yes & $7(88)$ & $11(52)$ & $25(32)$ & $14(38)$ & $1(20)$ \\
\hline No & $1(13)$ & $10(48)$ & $52(68)$ & $23(62)$ & $4(80)$ \\
\hline \multicolumn{6}{|c|}{ Educated by staff in safe injection } \\
\hline Yes & $6(75)$ & $11(58)$ & $17(52)$ & $19(56)$ & $2(67)$ \\
\hline No & $2(25)$ & $8(42)$ & $16(49)$ & $15(44)$ & $1(33)$ \\
\hline \multicolumn{6}{|l|}{ Was the education useful? } \\
\hline Yes & $6(100)$ & $11(100)$ & $14(82)$ & $19(100)$ & $2(100)$ \\
\hline No & $0(0)$ & $0(0)$ & $3(18)$ & $0(0)$ & $0(0)$ \\
\hline \multicolumn{6}{|l|}{ Educated in hygienic measures } \\
\hline Yes & $7(88)$ & $10(53)$ & $18(55)$ & $24(71)$ & $3(100)$ \\
\hline No & $1(12)$ & $9(47)$ & $15(46)$ & $10(29)$ & $0(0)$ \\
\hline \multicolumn{6}{|l|}{ Was the education useful? } \\
\hline Yes & $7(100)$ & $10(100)$ & $17(94)$ & $24(100)$ & $3(100)$ \\
\hline No & $0(0)$ & $0(0)$ & $1(6)$ & $0(0)$ & $0(0)$ \\
\hline \multicolumn{6}{|c|}{ Smokers educated in better smoking practices } \\
\hline Yes & $0(0)$ & $1(100)$ & $21(40)$ & $0(0)$ & $0(0)$ \\
\hline No & $1(100)$ & $0(0)$ & $31(60)$ & $0(0)$ & $0(0)$ \\
\hline \multicolumn{6}{|l|}{ Was the education useful? } \\
\hline Yes & & $1(100)$ & $18(86)$ & & \\
\hline No & & $0(0)$ & $2(9)$ & & \\
\hline Don't know & & & $1(5)$ & & \\
\hline \multicolumn{6}{|l|}{ Advised on OST } \\
\hline Yes & $3(38)$ & 7 (33) & $32(40)$ & $2(5)$ & $1(20)$ \\
\hline No & $5(63)$ & $14(67)$ & $48(60)$ & 35 (95) & $4(80)$ \\
\hline
\end{tabular}

to reach non-Danish service users and build up relationships as many service users speak poor Danish and poor English. This makes it difficult to develop a therapeutic rapport with the service users. Therapeutic rapport is an approach known to be important to engage service users and bridge to specialized care and drug treatment [33], 
and in the qualitative part of this national study, we found that forging relationships is seen as essential for referrals to health care [22]. Unlike in the injecting room, the staff cannot remain present in the smoking room due to a negative health risk for the staff due to second-hand smoke exposure. In the injection room, there are better opportunities for longer conversations between the staff and service users and thereby to allow rapport to develop gradually. Conversations with those who smoke have to take place elsewhere, typically the entrance of the facility which does not provide space for intimate conversations. Therefore, it is no surprise that only $40 \%$ of the participants in this facility who smoke drugs had been educated in better smoking practices. Nonetheless, $86 \%$ of those who had been educated found it useful (Table 7). Service users who smoke may need more harm-reducing interventions, like advice on OST, safer drug use methods, and health care education, than this study reveals.

One intention of having DCRs is to provide a setting for bridge building and guiding the service users to more specialized health care when needed [8]. The current analysis shows that staff in DCRs recommended service users that they seek medical attention, and $68 \%$ of those advised had also been in treatment for disease during the 2-year period the DCRs had existed at the time of the survey. The anonymous health care clinics located close to the DCRs are used by $30 \%$ of the service users. Since DCRs are organized in such a way that staff in the DCRs cannot provide basic nursing interventions like wound care, these clinics may play a major role in trying to secure medical attention for these service users. The short physical distance between the locations of DCRs and health clinics could account for the high number of positive referrals seen in the sample. It would make sense to offer basic nursing interventions such as wound care at the mobile DCRs that are operated further away from health clinics. Offering this basic health care service in the context of a DCR should be considered.

Only $57 \%$ of the participants reported having been educated in safe injection techniques and $60 \%$ in hygienic matters. However, further questioning as to whether participants find the education from the staff on injection practice useful shows that up to $98 \%$ of participants find it useful. We previously reported that staff are selective about time and place for education in safe injection practices and proper hygiene. It appears that the staff are successful at targeting service users who are able to apply the education [22]. This is similar to other studies indicating that DCRs are effective in facilitating educational advice regarding unsafe and unhygienic injection practice which contribute to less drug-related injury [15, 33, 34].

It is no surprise that only $30 \%$ of participants had been advised on how to get into drug treatment, as many of the Danish service users in the DCRs were already in contact with or had been in drug treatment. This study shows that the Danish DCRs promote contacts to specialized health care and provide a place that offers many services that the service users find important in order to eventually become drug free. According to a report from 2015 on Danish DCRs, more than 2359 nursing interventions on health-related matters, more than 1295 referrals to health care offers, and 354 referrals to substitution treatment were registered as having taken place at DCRs in 2014. Our finding on positive referrals is supported by other studies on positive referrals to drug treatment from DCRs [22, 33]. The qualitative part of this national study [22] indicates that the relationship formed between service users and staff and the trust service users have in the staff may be an important element for bridge building to specialized health care. Using the DCRs turns a stressful situation into an un-stressful situation for the service users. Inside the safe setting of a DCR, there is an opportunity for clients to learn about harm reductive practices and drug treatment options. More research into the relationship building that takes place at DCRs could contribute with more information about how this work influences service users and their motivation and success as they transit into drug treatment. Finally, more research in the service users who smoke and are of other nationality than Danish could contribute to important knowledge of the background of these people and open possibilities for harm-reducing care for them.

\section{Limitations}

There are several limitations to the study. The total service user pool was not possible to calculate due to discrepancy between registered number of DCR service users and service users active at the time of the survey. PWUD are a hidden population and the service users visiting the DCRs are anonymous. They register with an alias and some have several aliases. Some service users, often the ones who smoke or use cocaine, re-enter the DCRs more than 20 times a day. Therefore, the number of drug intake events does not correspond with the number of service users. Sometimes, service users who have been daily visitors for a period disappear. It is not known whether they are in treatment, hospitalized, incarcerated, or even dead but still they figure as registered clients. So the actual number of service users per month varies and is difficult to register. The statistical methods of the study are primarily bivariate analysis, determining simple descriptive associations.

It is also limitation that participants had to be able to speak Danish. Many DCR service users, especially those who smoke drugs, are of other nationalities other than 
Danish and are underrepresented in this study. Also, the study and survey were developed and embedded in a Danish context and therefore may not be readily generalized to populations of DCR service users in other countries.

\section{Conclusions}

The study contributes information on self-reported drug intake behavior of DCR service users' health and contact to the primary sector and drug treatment. In only 2 years, Denmark has succeeded in opening five DCRs and attracting PWUD with a prolonged chronic history. Danish DCRs provide a positive environment for staff to establish relationships with service users which includes offering advice and education on medical, technical, hygienic, and drug treatment issues as well as bridging access to specialized health care. At present, health providers in Copenhagen are challenged when communicating with DCR service users of other nationalities other than Danish as they have been less in OST and may not be advised at the same rate as the Danish service users. Also, service users who primarily smoke their drugs and are of other nationalities other than Danish are underserved; more research on clients who smoke their drugs is needed. Danish DCRs have been organized so that staff cannot provide medical attention within the DCR; therefore, anonymous health clinics located near the DCRs may play an important role in the health of the service users. When operating DCRs at a location further away from a health clinic, a larger body of nursing interventions such as wound care should be considered and possibly integrated into the current services.

\section{Additional files}

Additional file 1: Survey Questionnaire Danish version. (PDF $130 \mathrm{~kb}$ )

Additional file 2: Survey Questionnaire English version. (PDF 203 kb)

\section{Abbreviations}

DCR: Drug consumption room; PWUD: People who use drugs; OST: Opioid substitution treatment

\footnotetext{
Acknowledgements

Acknowledgement is given to leaders and staff of the Danish DCRs for assisting the researchers of this study in gaining access to the DCR. Without their help, this study would not have been possible. The authors would also like to acknowledge all the DCR service users who gave their time to participate in the survey. We would also like to acknowledge Morten Hesse and Birgitte Tylstrup from the Centre for Alcohol and Drug Research, Aarhus University, Denmark, for the help with the development of the survey questionnaire as well as statistician Steen Ladelund, Clinical Research Center, Copenhagen University Hospital, Hvidovre, Denmark, for the statistical analysis. Finally, we would like to acknowledge Professor Dr. Paul J. Schaeffer, Miami University, Ohio, for assistance with the editing of the manuscript.
}

\section{Funding}

The project has been funded by Metropolitan University College,

Copenhagen, Denmark, and supported with a grant from Sister Marie Dalgaards Foundation. The funding body played no role in the design of the study and collection, analysis, and interpretation of data and in writing the manuscript.

\section{Availability of data and materials}

The survey questionnaire used in this article is freely available to any scientist wishing to use it in both a Danish and an English version (Additional files 1 and 2). The dataset analyzed during the current study is not publicly available as it contains unpublished results. However, it is available from the corresponding author on reasonable request.

\section{Authors' contributions}

NK and SL designed the study. NK, JT, ECT, and SL developed the questionnaire. NK, JT, and ECT undertook data collection. ECT analyzed the data. ECT and NK prepared the first draft of the article. All authors contributed to the revision of the manuscript. All authors read and approved the final manuscript.

\section{Competing interest}

The authors declare that they have no competing interest.

\section{Consent for publication}

The manuscript does not include individual person's data, and therefore, consent for publication is not applicable.

\section{Ethics approval and consent to participate}

Prior to data collection, the project was accepted by the Danish Data Protection Agency (J.no 2014-41-2784). Participants were informed that participation was voluntary and anonymous and that they could withdraw from the study at any time without any consequences.

\section{Author details}

'Department of Nursing, Metropolitan University College, Copenhagen, Denmark. ${ }^{2}$ Cowi, Lyngby, Denmark.

Received: 19 February 2016 Accepted: 15 September 2016

Published online: 07 October 2016

\section{References}

1. Rhodes T. Risk environments and drug harms: a social science for harm reduction approach. Int J Drug Policy. 2009;20(3):193-201.

2. Rhodes T, Kimber J, Small W, Fitzgerald J, Kerr T, Hickman M, Holloway G. Public injecting and the need for 'safer environment interventions' in the reduction of drug-related harm. Addiction. 2006;101(10):1384-93.

3. Rhodes T, Watts L, Davies S, Martin A, Smith J, Clark D, Craine N, Lyons M. Risk, shame and the public injector: a qualitative study of drug injecting in South Wales. Soc Sci Med. 2007;65(3):572-85.

4. Ebright JR, Pieper B. Skin and soft tissue infections in injection drug users. Infect Dis Clin North Am. 2002:16(3):697-712.

5. Coull AF, Atherton I, Taylor A, Watterson AE. Prevalence of skin problems and leg ulceration in a sample of young injecting drug users. Harm Reduct J. 2014;11:22-7517-11-22.

6. Ministry of Health and Prevention, Denmark. Law Amending the Law on Narcotic Substances. 2012. p. 606

7. Ministry of Health and prevention, Denmark. Bill amending the law on narcotics. 2011

8. Ministry of Health and Prevention Denmark. Evaluation of Existing Drug Consumption Rooms. 2015. p. 1.

9. Ministry of Health Denmark. The Narcotic Situation in Denmark 2015. National data. 2015. p. 1.

10. Ministry of Health Denmark. The Narcotic Situation in Denmark 2014. National Data. 2014. p. 1

11. Hedrich D, Kerr T, Dubois Arber F. Drug consumption facilities in Europe and beyond. 2010. p. 305-32. Harm Reduction: Evidence, Impacts, and Challenges.

12. Schäffer D, Stöver $H$, Weichert L. Drug consumption rooms in Europe Models, best practice and challenges. Amsterdam: European Harm Reduction Network; 2014. 
13. DeBeck K, Kerr T, Bird L, Zhang R, Marsh D, Tyndall M, Montaner J, Wood E. Injection drug use cessation and use of North America's first medically supervised safer injecting facility. Drug Alcohol Depend. 2011:113(2-3):172-6.

14. Scherbaum N, Specka M, Bombeck J, Marrziniak B. Drug consumption facility as part of a primary health care centre for problem drug users which clients are attracted? Int I Drug Policy. 2009;20(5):447-9.

15. Fast $\mathrm{D}$, Small W, Wood E, Kerr T. The perspectives of injection drug users regarding safer injecting education delivered through a supervised injecting facility. Harm Reduct J. 2008;5:32-7517-5-32.

16. Small W, Wood E, Lloyd-Smith E, Tyndall M, Kerr T. Accessing care for injection-related infections through a medically supervised injecting facility: a qualitative study. Drug Alcohol Depend. 2008:98(1-2):159-62.

17. Kerr T, Small W, Moore D, Wood E. A micro-environmental intervention to reduce the harms associated with drug-related overdose: evidence from the evaluation of Vancouver's safer injection facility. Int J Drug Policy. 2007;18(1):37-45.

18. Marshall BD, Milloy MJ, Wood E, Montaner JS, Kerr T. Reduction in overdose mortality after the opening of North America's first medically supervised safer injecting facility: a retrospective population-based study. Lancet. 2011;377(9775):1429-37.

19. Milloy MJ, Kerr T, Tyndall M, Montaner J, Wood E. Estimated drug overdose deaths averted by North America's first medically-supervised safer injection facility. PLoS One. 2008;3(10):e3351.

20. Wood E, Tyndall MW, Li K, Lloyd-Smith E, Small W, Montaner J, Kerr T. Do supervised injecting facilities attract higher-risk injection drug users? Am J Prev Med. 2005;29:126-30.

21. Kinnard E, Howe C, Kerr T, Skjodt Hass V, Marshall B. Self-reported changes in drug use behaviors and syringe disposal methods following the opening of a supervised injecting facility in Copenhagen, Denmark. Harm Reduct J. 2014;11(1):29

22. Kappel N, Toth E, Tegner J, Lauridsen S. A qualitative study of how Danish drug consumption rooms influence health and well-being among people who use drugs. Harm Reduct J. 2016;13(1):20.

23. Hagensen P, Christiansen R, Christensen I. Stofindtagelsesrummets første tre måneder. En Monitorering. 2. oktober-31.december 2012. Copenhagen: Maendenes Hjem; 2013.

24. Sundhedsstyrelsen. National Report (2011 data) to the EMCDDA by the Reitox National Focal Point. Denmark: New Development, Trends, and in-Depth Information on Selected Issues; 2012. p. 1-115.

25. Creswell JW. A concise introduction to mixed methods research. 1.st. ed. London: Sage Publishing Inc; 2015.

26. Enalyzer Survey Solution: Enalyzer Survey Software. 2015. http://www. enalyzer.com/

27. Odense K. Social- og arbejdsmarkedsforvaltningen Socialcentret: Stofindtagelsesrummet. Status for 2014. 2015. p. 1.

28. Aarhus K. Sociale forhold og beskaeftigelse: Afrapportering Stofindtagelsesrum i Aarhus kommune. 2015. p. 1.

29. Koebenhavns Kommune: Koebenhavns Kommunes afrappportering om stofindtagelsesrum til Ministeriet for Sundhed og Forebyggelse. 2015, 1(1).

30. IBM SPSS software: IBM SPSS Statistics 22. 2015. http://www-01.ibm.com/ software/analytics/spss/.

31. R Core Team: R: A language and environment for statistical computing. $R$ Foundation for Statistical Computing, Vienna, Austria. 2014. URL http://www.R-project.org/.

32. Vandenbroucke J, von Elm E, Altman D, Gøtzsche P, Mulrow C, Pocock S, Poole C, Schlesselman J, Egger M. Strengthening the Reporting of Observational Studies in Epidemiology (STROBE): explanation and elaboration. Int J Surg. 2014;12(12):1500-24.

33. Kimber J, Mattick RP, Kaldor J, Van Beek I, Gilmur S, Rance JA. Process and predictors of drug treatment referral and referral uptake at the Sydney Medically Supervised Injecting Centre. Drug Alcohol Rev. 2008;27(6):602-12.

34. Salmon A, Dwyer R, Jauncey M, van Beek I, Topp L, Maher L. Injectingrelated injury and disease among clients of a supervised injecting facility. Drug Alcohol Depend. 2009;101(1-2):132-6.

\section{Submit your next manuscript to BioMed Central and we will help you at every step:}

- We accept pre-submission inquiries

- Our selector tool helps you to find the most relevant journal

- We provide round the clock customer support

- Convenient online submission

- Thorough peer review

- Inclusion in PubMed and all major indexing services

- Maximum visibility for your research

Submit your manuscript at www.biomedcentral.com/submit
Biomed Central 